\title{
Contribuições do Portfólio para a avaliação do aluno universitário
}

\author{
VÂNIA MARIA DE OLIVEIRA VIEIRA* \\ CLARILZA PRADO SOUSA**
}

\section{RESUMO}

Este artigo constitui-se em síntese de uma pesquisa mais ampla e tem o propósito de investigar se a ideia do Portfólio, implantada em uma instituição, vem modificando a forma de pensar a avaliação, no âmbito da formação de educadores. O referencial teórico foi alicerçado em autores do campo da avaliação educacional e nos fundamentos da Teoria das Representaçóes Sociais. As trilhas metodológicas percorridas possibilitaram-nos a coleta e o processamento de um conjunto diversificado de informaçóes. Utilizando os programas EVOC e ALCESTE, foi possível realizar análises específicas dos dados. Os resultados permitiram identificar três grupos de alunos: os que aprovam a avaliação realizada por Portfólio; os que desaprovam; e os que aprovam, mas com ressalvas. Tais resultados nos levam a considerar a necessidade de aprofundar argumentos no sentido de favorecer os processos de ancoragem que irão facilitar não somente a aceitação do Portfólio, mas também sua possível utilização quando esses alunos desenvolverem sua prática como professores.

Palavras-chave: representação social, avaliação da educação, formação de professores, ensino superior.

\section{RESUMEN}

Este artículo es la síntesis de una investigación más amplia y tiene el propósito de indagar si la idea del Portfolio, implementada en una institución, está cambiando la forma de pensar la evaluación en el ámbito de la formación de los educadores. El marco teórico se basa en autores

\footnotetext{
* Professora titular da Universidade de Uberaba (vaniacamila@uol.com.br).

** Professora da Pontifícia Universidade Católica de São Paulo (PUCSP) e pesquisadora sênior da Fundaçáo Carlos Chagas (clarilza.prado@uol.com.br).
} 
del campo de la evaluación educativa y en los fundamentos de la Teoría de las Representaciones Sociales. Los caminos metodológicos recorridos nos han posibilitado la recolección y el procesamiento de un conjunto diversificado de informaciones. Utilizando los programas EVOC y ALCESTE se pudo realizar un análisis específico de los datos. Los resultados permitieron identificar tres grupos de alumnos: los que aprueban la evaluación realizada por Portfolio, los que desaprueban; y los que aprueban, pero con restricciones. Tales resultados nos llevan a considerar la necesidad de profundizar los argumentos para favorecer los procesos de fundamentación que facilitarán no sólo la aceptación del Portfolio, sino también su posible utilización cuando estos alumnos desarrollen sus prácticas como profesores.

Palabras clave: representación social, evaluación de la educación, formación de profesores, enseñanza superior.

\section{ABSTRACT}

This article is a part of a broader study aimed at investigating if the use of a Portfolio as a means of assessment in an educational environment has been changing the way of thinking about assessment in the field of teacher training. The study is based on authors involved in educational assessment and also on the Theory of Social Representations. The methodology used made possible the processing of a varied set of information. Specific analyses were conducted by means of EVOC and ALCESTE programs. The results led to the identification of three groups of students: those who approve of this assessment system, those who disapprove of it, and also those who approve of it but hold restrictions. These findings point to the need to further probe into the theoretical arguments in favor of studies involving the Portfolio, not only to make it more widely accepted, but also to promote its possible use in the future when these students/ teachers develop their own practices as teachers.

Keywords: social representations, curse evaluation, teacher education, higher education. 
Os processos de avaliação da aprendizagem do aluno universitário, no contexto da sala de aula, realizada pelo professor, está passando por nova fase. Há o reconhecimento, entre os educadores do ensino superior, que a avaliação, apenas por meio de provas, não permite uma análise adequada do aluno. Também entendem que náo terão condiçôes de elaborar, sozinhos, provas tecnicamente bem construídas como as realizadas por especialistas da área para os sistemas nacionais de avaliação.

Assim, os professores que estáo conscientes deste problema têm nos apontado a seguinte questão:

Nossas provas não podem ter a qualidade técnica de provas elaboradas por especialistas; no entanto, temos condiçōes de avaliar o aluno de forma mais efetiva do que utilizando uma única prova. Quais os processos que poderiam ser usados para promover uma avaliação mais efetiva e não apenas repetição de provas realizadas por avaliações de sistemas nacionais, como o Enadel?

Este texto é uma tentativa de apresentar a esses professores outra metodologia possível de avaliação do aluno universitário. Sua vantagem sobre o uso exclusivo de provas é que ela permite a correção da análise e do julgamento a respeito do desempenho do aluno durante o curso, favorece amostras de comportamentos dos estudantes em várias situaçóes de ensino, induz o aprendiz a refletir acerca de seu próprio desempenho, orienta-o mais claramente em direção a determinados pontos fundamentais do curso e, além disso, permite ao professor uma avaliação mais ampla do aluno, indicando suas facilidades e dificuldades. Não se pretende com isso criticar as avaliaçóes de sistemas realizadas com base em provas, pois é esse justamente o tipo de instrumento indicado por um processo nacional que busca amostras de comportamentos, de aprendizagens, selecionadas para avaliar o desempenho de um curso, de uma faculdade, a educação superior.

Não se trata da avaliaçáo da aprendizagem de determinado aluno, pois compete ao professor analisar o desempenho específico individual de seus aprendizes, identificando aqueles que apresentam dificuldades no decorrer do curso, dificuldades que podem ir além do domínio de conteúdos que são exigidos em determinada formação. O desempenho relativo ao domínio de conteúdo, obtido por meio de provas, pode ser um dos instrumentos de análise, mas não o único a ser utilizado.

\footnotetext{
${ }^{1}$ O Exame Nacional de Desempenho dos Estudantes (Enade), que integra o Sistema Nacional de Avaliação da Educaçáo Superior (Sinaes), tem por objetivo aferir o rendimento dos alunos dos cursos de graduação em relação aos conteúdos programáticos, suas habilidades e competências.
} 
A avaliação realizada unicamente por provas, como comenta Vianna (1993), nem sempre evidencia as dificuldades específicas de cada aluno. O caráter episódico das avaliaçóes bimestrais náo acompanha o desenvolvimento do aluno de forma estruturada, náo consegue detectar como ele adquire suas aprendizagens e, assim, acaba apenas classificando-o no interior de uma classe. Novamente, compreende-se que em uma avaliação nacional haja certa hierarquização de domínios de habilidades e competências, enquanto função do Estado - de regular as aprendizagens desenvolvidas nas escolas, em um curso, em uma universidade - o que não significa hierarquizar instituiçóes ou universidades. Contudo, no âmbito da sala de aula, a avaliação de alunos universitários segue o modelo da avaliação exclusivamente por meio de provas, do tipo da avaliaçáo de sistema, que tende a náo auxiliar o curso a melhorar seu desempenho. Diríamos, são dois métodos de avaliação diferentes que exigem metodologias e técnicas diferentes. $\mathrm{O}$ desconhecimento desses dois domínios de avaliação tem permitido, por um lado, críticas superficiais aos procedimentos das avaliaçóes de sistema e, por outro, imitaçóes dessa metodologia de avaliação para o domínio micro, na sala de aula, de forma inadequada.

Assim, para ajudar os alunos a conseguirem um resultado satisfatório no Enade, algumas Instituiçóes de Ensino Superior (IES) intensificam processos avaliativos, utilizando instrumentos semelhantes aos das avaliaçóes em larga escala. Desse modo, têm a ilusão de que estáo preparando seus alunos para que melhorem seu desempenho no Enade. Perdem com isso a possibilidade de ampliar e aprofundar o processo avaliativo e, principalmente, de identificar e corrigir as defasagens de seus alunos.

Nesse contexto, as IES têm um compromisso claro com o desempenho e devem assumir a avaliação de alunos. Compete ao professor e aos coordenadores identificar processos que permitam avaliar melhor o desempenho de seus alunos e, em conjunto com as IES, desenvolver métodos para melhorar a aprendizagem.

Apresentamos, neste texto, uma metodologia, reconhecendo que não é a única, mas que acreditamos poderá, efetivamente, contribuir para aperfeiçoar o diagnóstico e aprimorar o ensino no âmbito das IES: o Portfólio, que poderá ajudar as instituiçôes interessadas explicitamente no desenvolvimento do desempenho do aluno e na formação de seus estudantes.

O prefixo port vem do latim e significa "transportar". Segundo o dicionário Longman Dictionary of Contemporary English, 1995, a palavra folio significa: "1- um livro feito com páginas grandes. 2- uma única folha de papel ou página de um livro". 
No dicionário Houaiss (2001) tem a seguinte definição:

PORTFÓLIO s.m. (pal. Ing.) Pasta flexível para guardar ou transportar papéis, documentos, fotos, etc. / Álbum ou pasta, de folhas soltas ou não, com material em geral fixado (p. ex., leiautes de publicidade, fotos, trabalhos de um artista) para apresentação a outra pessoa (p. ex., clientes, editores, agências de modelos). (Forma port. pref.: Portfólio).

No campo da educação, Hernández (1998) define Portfólio como:

Continente de diferentes classes de documentos (notas pessoais, experiências de aula, trabalhos pontuais, controle de aprendizagem, conexôes com outros temas fora da Escola, representaçôes visuais, etc.) que proporciona evidências do conhecimento que foi construído, das estratégias utilizadas e da disposição de quem o elabora em continuar aprendendo. (p. 100)

De acordo com essa definição, podemos afirmar que o Portfólio é muito mais que a reuniáo de trabalhos ou materiais colocados numa pasta. Além de selecionar e ordenar evidências de aprendizagem do aluno, ele possibilita também identificar questóes relacionadas ao modo de os estudantes e educadores refletirem sobre os reais objetivos de sua aprendizagem, quais foram cumpridos, e os que não foram alcançados.

Nascimento e Lassance (2000) assim se pronunciam ao definir Portfólio:

Portfólio (também chamado de dossiê ou coletânea de trabalhos e realizações do autor) é uma descriçáo ou resumo pessoal ou institucional que o autor faz de suas atividades, em função de um processo educativo ou outras ocupaçôes. O conceito foi ampliado a partir da experiência de uso nas áreas de arquitetura, artes e comunicação. As diversas finalidades do Portfólio permitem aos avaliadores definir o espaço e o tempo em que a produção ou desempenho do sujeito deve ser considerado. (p. 44)

Para esses autores, o Portfólio pode compreender a compilação de trabalhos realizados pelos alunos, como: registro de visitas, resumos de textos, projetos e relatórios de pesquisas, anotações de experiências, ensaios autorreflexivos e outros (p. 44).

Como afirma Vieira (2003): "A forma de avaliar traz implicitamente as concepçóes de aprender e ensinar de quem avalia". Nesses termos, uma avaliaçáo excludente, classificatória, autoritária reflete um processo de ensinar com a mesma orientação. A avaliação realizada pelo professor traduz sua forma de ver o processo 
de ensino e aprendizagem e indica a possibilidade de mudança que ele constrói no cotidiano com seus alunos.

Com base em estudo realizado em uma universidade privada do Estado de Minas Gerais, que havia implantado o Portfólio como instrumento de avaliação nos cursos de licenciaturas, resolvemos investigar como os alunos estão vendo essas mudanças, bem como se essa nova ferramenta possibilitaria desenvolver representaçóes mais positivas em relação aos cursos de formação de professores.

Resumidamente, procuramos responder às seguintes questóes: quais os significados sobre a avaliação da aprendizagem estáo sendo construídos pelos alunos, nos cursos de licenciaturas, com o uso do Portfólio como instrumento avaliativo? As significaçóes modificam a visão de uma avaliação excludente, classificatória, autoritária, como é muitas vezes concebida?

A figura 1 apresenta sucintamente o problema, o objeto, os objetivos e a hipótese desta pesquisa.

Figura 1 - Síntese do problema, objeto, objetivo e hipótese desta pesquisa

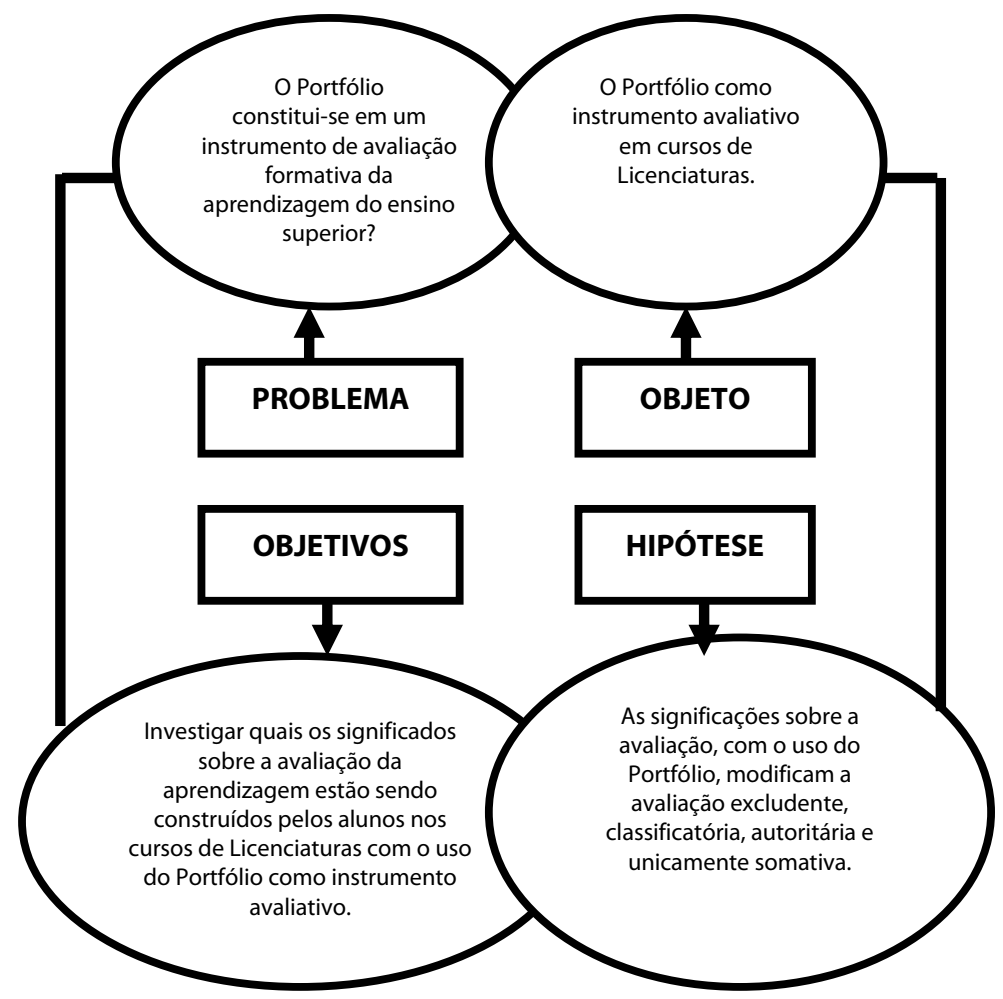




\section{A PESQUISA}

A pesquisa orientou-se por uma modalidade de estudo qualitativa e teve o respaldo da Teoria das Representaçóes Sociais, explicitada por Moscovici (2003), Jodelet (2001) e Sá (2002), para apoiar a análise da visão dos alunos sobre o processo que estavam vivenciando, as expectativas que tinham com uma avaliação no ensino superior, bem como os efeitos desse tipo de avaliação no processo de ensino e aprendizagem dos professores e alunos.

Procuramos, assim, compreender como o sentido e o significado dessa avaliação têm sido construídos pelos discentes de uma instituição escolar, a partir da experiência com o Portfólio. Ao analisar tais significados, com o apoio da metodologia e estrutura teórica das representaçóes sociais, foi possível familiarizar-nos com os significados construídos por grupos de sujeitos pertencentes ao mesmo contexto social - os alunos dos cursos de licenciaturas da IES analisada.

A construção de significados e sentidos atribuídos à prática avaliativa é um processo psicossocial, em que se vivenciam confrontos, convergências, crenças, aspectos afetivos e representaçóes construídas e reconstruídas, que irão interferir no processo avaliativo. A pesquisa realizada enfocou a análise do Portfólio, considerando essa perspectiva psicossocial.

O grupo de investigação desta pesquisa foi composto de 211 licenciandos concluintes de 8 licenciaturas: Letras - Português/Inglês, Letras - Português/Espanhol, História, Matemática, Biologia, Química, Pedagogia e Pedagogia Especial.

Para a coleta dos dados, foram utilizados dois questionários com questóes fechadas, abertas e de associaçáo livre. O primeiro questionário, com 20 perguntas, objetivou, nas 19 primeiras, delinear o perfil dos alunos quanto a sexo, idade, estado civil, escolaridade e ocupaçáo dos pais, renda familiar, afinidade com o curso, entre outros. A última questão teve o propósito de investigar e identificar o significado do Portfólio para cada sujeito. O segundo questionário, com 12 questóes, sendo 9 fechadas e 3 abertas, teve por objetivo identificar as representaçóes sociais dos alunos sobre o que revela o Portfólio como instrumento de avaliação da aprendizagem.

A aplicação dos questionários foi precedida por pedido formal de autorização escrita à diretora do Instituto de Educaçáo, aos gestores e, principalmente, a assinatura do Termo de Consentimento Livre e Esclarecido² pelos alunos de cada curso.

2. O Conselho de Ética tornou-o obrigatório para a realização de pesquisa com seres humanos; consiste em explicitar aos sujeitos as finalidades e os objetivos da pesquisa, informar os instrumentos a serem utilizados e obter consentimento livre para a coleta de informaçóes. 
Os questionários foram aplicados no decorrer das aulas, em datas marcadas pelos professores, que gentilmente cederam seus horários. Cada questionário levou aproximadamente uma hora/aula para ser aplicado. Durante esse tempo, o pesquisador manteve-se presente, para esclarecer eventuais dúvidas, e alguns professores também ofereceram ajuda, pois permaneceram na sala.

\section{ANÁLISE DOS RESULTADOS}

A análise foi realizada inicialmente com os dados do perfil dos alunos, obtidos na aplicação do questionário de questôes fechadas; posteriormente, utilizando o software EVOC $^{3}$, analisamos os dados obtidos com base nas associaçôes livres. Procuramos avaliar as justificativas utilizando as análises de conteúdo de Franco (2003). Para a organizaçáo das análises das questóes fechadas apenas utilizamos frequência e porcentagem; e, finalmente, empregamos o software ALCESTE ${ }^{4}$ para apoiar a análise das questóes abertas. Cada uma das fases permitiu não somente ampliar as dimensóes de análise como também aprofundar as hipóteses interpretativas geradas em cada uma delas.

\section{COMENTANDO OS RESULTADOS}

\section{Perfil dos sujeitos}

Os sujeitos da pesquisa apresentaram um perfil que resumidamente poderia ser assim descrito:

- a maior representatividade encontra-se na faixa etária até 24 anos, prevalecendo o sexo feminino e estado civil solteiro, seguido de casado;

- $\quad 87 \%$ dos alunos possuem uma religião, com predomínio da católica, seguida da espírita;

- a maioria dos pais não concluiu o ensino fundamental; apenas $13 \%$ têm curso superior; e, quanto à profissão, um número significativo é de aposentados, do lar, ou já falecidos;

- $\quad$ predomina a renda mensal familiar de até $\mathrm{R} \$ 2000,00$, incluindo a do licenciando, quando trabalha;

\footnotetext{
${ }^{3}$ Optamos pelo tratamento de dados do programa EVOC-Logiciel EVOC 99, Version 99, que permite a análise de evocaçóes e combina a frequência com a ordem de emissão de palavras. Esse programa busca criar um conjunto de categorias organizadas em torno desses termos, para assim confirmar as indicaçóes sobre seu papel organizador das representaçóes.

${ }^{4}$ Software que se presta à análise quantitativa de dados textuais. O processo de execução do programa tem como base de cálculo as leis de distribuição do vocabulário e objetiva auxiliar na realização da análise lexical das entrevistas.
} 
- a maioria, ou seja, 77\% dos alunos, optou pela licenciatura por gostar do curso e por desejar ser professor;

- dentre os licenciandos que trabalham, 54\% atuam na educaçáo, com predomínio da educação infantil, seguido do ensino fundamental;

- $82 \%$ dos estudantes costumam ler outros livros além dos recomendados pelo curso e $95 \%$ utilizam o computador para realização das atividades escolares.

\section{Análise das associaçóes livres: evocaçáo das palavras associadas ao Portfólio}

A análise das associaçóes livres com a utilização do EVOC teve como objetivo, neste estudo, identificar a estrutura das representaçóes sociais dos alunos licenciandos sobre o portfólio. A análise das evocaçóes dos sujeitos a partir da palavra "Portfólio", quando tratada pelo programa EVOC, permitiu-nos desvelar importantes significaçóes associadas ao termo.

O programa combinou a frequência com a ordem da emissão das palavras e produziu um quadrante, que representa os quatro agrupamentos das emissóes, como mostra a figura 2:

Figura 2 - Visão geral dos quatro agrupamentos das emissões das palavras

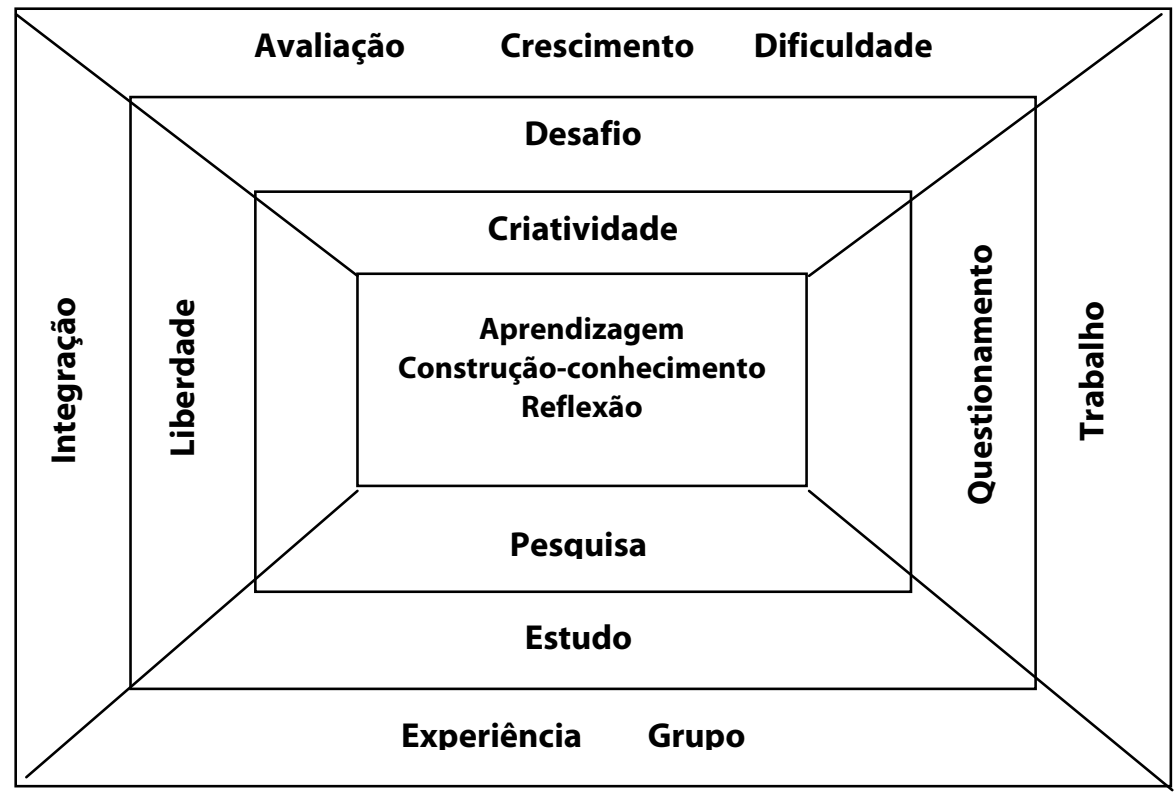


No quadrante central, concentram-se as palavras evocadas com mais frequência e mais prontamente pelos alunos: aprendizagem, construçáo-conhecimento e reflexáo. Provavelmente, revelam-se como nucleares, em relaçáo ao conteúdo representacional ligado ao uso do Portfólio, por seu caráter prototípico ou por sua saliência. Justificativas como: "Ao construir o Portfólio estudamos novamente o conteúdo, o que nos ajuda a sanar as dúvidas" (sujeito 57, curso 3); "A aprendizagem deve ser o resultado da construção do conhecimento que se busca na realização do Portfólio" (sujeito 165, curso 8); “(...) quando fazemos o Portfólio, mostramos a construção de nossas aprendizagens, as dificuldades e o que fizemos para superá-las" (sujeito 91, curso 5) parecem traduzir o sentimento e o que pensam os licenciandos ao lembrar da experiência de uso do Portfólio como instrumento de avaliação.

No segundo quadrante, temos as palavras criatividade e pesquisa, indicando que foram citadas mais de 29 vezes, e a média da ordem da emissão é maior que 3. A recorrência do emprego desses termos indica, possivelmente, que são elementos importantes da representação, mas não se afirmam como núcleo central.

As argumentaçôes: "Para desenvolver um bom Portfólio, ter criatividade é fundamental" (sujeito 112, curso 6); "Considero que a partir da pesquisa alcançamos o saber, a criatividade e o sentimento de coletividade. O Portfólio nos permite adquirir conhecimentos através da pesquisa realizada com grande dedicação e responsabilidade" (sujeito 145, curso 7); "A pesquisa é a melhor forma de adquirir conhecimento" (sujeito 145, curso 7) parecem evidenciar que a criatividade e a pesquisa são componentes importantes na construção do Portfólio.

O terceiro quadrante, representado pelas palavras desafio, estudo, liberdade e questionamento, indica que esse grupo apresenta frequência inferior a 29 vezes e, ao contrário do quadrante 2 , a emissão das palavras é menor que 3 . As palavras representativas desse quadrante apresentam como justificativas: "Teoricamente o Portfólio é a reunião de nossas aprendizagens. Na prática, escrevemos não somente o que aprendemos, mas o que somos orientados a escrever; afinal, o Portfólio reprova, e de nada adianta discutir com quem já tem sua opinião pré-formada, ainda mais quando esse alguém detém o poder sobre a minha vida” (sujeito 87, curso 5); "O Portfólio é o que me faz estudar um pouco mais e reconhecer e conhecer o que sei de conteúdos" (sujeito 25, curso 1); "O Portfólio dá liberdade para o aluno desenvolver um bom trabalho, mostrando o que aprendeu verdadeiramente" (sujeito 154, curso 7) e traduzem um sentimento ambivalente dos alunos em relação ao uso do Portfólio. Reconhecem a pesquisa como fator preponderante na construção do Portfólio, mas, ao mesmo tempo, percebem esse estudo como 
um desafio, pois pode ser ameaçador por parte de alguns professores. Embora atribuam ao Portfólio a característica de liberdade, também o consideram obrigatório e reprovador; um instrumento em que é permitido escrever somente o que o orientador quer. Ainda que essas palavras tenham sido citadas poucas vezes em relação às dos outros quadrantes, essa representação de Portfólio, provavelmente, pertence a um subgrupo de alunos.

As palavras situadas no quarto quadrante - avaliaçáo, crescimento, dificuldade, experiência, grupo, integraçáo e trabalho - constituem os elementos periféricos da representação mais superficiais, mais flexíveis, heterogêneos e próximos das experiências cotidianas. Apresentam frequência inferior a 29 vezes e a emissão das palavras é maior que 3 .

Justificativas citadas por alguns sujeitos, como: "Com o uso da aplicação do Portfólio no curso, a avaliação nos deixou mais tranquilos, em substituição às provas tradicionais" (sujeito 49, curso 3); “(...) através do Portfólio percebe-se um crescimento no convívio com o grupo, no conteúdo e também intelectualmente" (sujeito 129, curso 6); "Acho que valeu a experiência com o Portfólio, pois através dele podemos construir nossos conhecimentos" (sujeito 89, do curso 5); "Desde que você tenha uma orientação correta e saiba o que fazer, o Portfólio faz com que a integração dos conteúdos seja mais compreensível” (sujeito 102, curso 5) demonstram representaçóes acerca do Portfólio.

O sistema periférico, por ser mais flexível, tem a propriedade de modificar-se mais facilmente do que o núcleo central. Villas Boas (2003, p.70) assinala, lembrando Abric (2000), que o núcleo periférico "praticamente assume a função de proteção desse núcleo na medida em que permite a adaptação a uma dada situação, sem que isso implique a modificação do núcleo central", e acrescenta: "a sua determinação está mais ligada ao contexto imediato e às características individuais".

$\mathrm{Na}$ segunda fase do estudo, procuramos organizar todas as palavras e justificativas que tentavam descrever o que o Portfólio significava para esses alunos. Nesse processo de análise identificamos seis categorias de sentido.

\section{a) Os alunos sentem-se "incomodados" ou náo consideram útil o uso do Portfólio}

Agrupamos nessa categoria textos com palavras e expressóes que apontam o Portfólio como um instrumento de avaliação sem utilidade; ao mesmo tempo, os alunos sentem-se incomodados ao fazê-lo. As palavras: inútil, contraditório, não avaliativo, caos são apontadas como definidoras de Portfólio. A justificativa: "No meu 
curso não acho que ele auxilia no processo de formação, e também não concordo que seja uma forma de avaliar o aluno. Além disso, é muito cansativo fazê-lo (...)" caracteriza essa categoria.

Apenas sete alunos, ou seja, 4,1\% dos licenciandos, representam essa categoria, o que nos permite afirmar que poucos consideram o Portfólio um "incômodo" e um instrumento avaliativo desnecessário. Fazem parte desse grupo um sujeito do curso de Matemática e seis sujeitos do curso de Biologia.

\section{b) Sentem-se "bem" construindo o Portfólio e consideram-no um instru- mento confiável de avaliaçáo}

Compóem essa categoria 47 sujeitos, ou seja, 28\% dos licenciandos. Palavras como: desenvolvimento, conhecimento, autonomia, construção, aprendizagem e descobrimento aparecem com freqüência nas respostas. Os textos que justificam a escolha dessas palavras parecem revelar que os alunos além de aprovarem o Portfólio consideram-no um instrumento de avaliação confiável. Caracterizam essa categoria as argumentaçóes: "O processo permite evoluirmos, ao longo do curso, em vários aspectos do conhecimento"; "Através do Portfólio descobrimos horizontes fantásticos e sem ele não seria possível”.

\section{c) Apontam o Portfólio como facilitador na construçáo da aprendizagem}

Compóem essa categoria as respostas de 71 licenciandos, perfazendo um total de $42,0 \%$ de sujeitos entrevistados. Os textos que formam essa categoria apresentam palavras e justificativas que apontam o Portfólio como facilitador da aprendizagem. Liberdade, reflexão, aprendizagem, conhecimento e construção da aprendizagem foram algumas das mais citadas. As justificativas: "O Portfólio nos dá a oportunidade de construir e acompanhar nosso crescimento durante o curso, possibilitando comparar nosso desenvolvimento e crescimento com os anos anteriores"; "Só se entende e aplica um conhecimento se este for construído, debatido e compreendido" caracterizam essa categoria e parecem evidenciar que o Portfólio auxilia na construção e organização das aprendizagens. $\mathrm{O}$ texto mostra também a importância da reflexão no processo de construção de conhecimento.

\section{d) Apontam aspectos dificultadores na construção do Portfólio}

Dos 168 sujeitos entrevistados, 6,5\%, ou seja, 11 alunos, usaram as palavras: sacrifício, reflexâo, difícil, complicado e individual para apontar as dificuldades en- 
contradas para a construção do Portfólio. Argumentaçôes do tipo: "Até hoje não sei muito bem como fazer o Portfólio e ele é muito trabalhoso, por isso tenho que sacrificar-me omitindo outras atividades para fazê-lo"; "É muito difícil para eu refletir, por isso não gosto do Portfólio"; "O Portfólio deveria ser individual, pois assim estaria avaliando realmente quem o fez" caracterizam essa categoria.

\section{e) Compreendem que o Portfólio é superior à avaliação classificatória - seletiva e excludente}

Aprendizagem significativa, construção, reflexão, chance e avaliação emancipatória são algumas das palavras citadas pelos alunos dessa categoria, para demonstrar que o Portfólio é superior à avaliação classificatória - seletiva e excludente. Compóem essa classe apenas $11,2 \%$ dos alunos entrevistados, ou seja, 19 sujeitos. Definem essa categoria as expressóes: "Através do Portfólio podemos aprender e construir o que é importante para nós, e o conteúdo náo fica fragmentado como nas provas quantitativas"; "Sou a favor"; "O Portfólio, em minha opinião, é um processo, uma construção significativa da aprendizagem, maior e mais abrangente que uma prova tradicional".

\section{f) Demonstram que a construçáo do Portfólio produz resultado satisfa- tório, mas exige tempo e dedicaçáo}

Essa categoria é composta de 14 alunos, representando apenas 8,3\% dos licenciandos entrevistados. Palavras e expressóes ditas por esse grupo parecem revelar que aprovam o uso do Portfólio como instrumento avaliativo, mas consideram a sua construção cansativa, por demandar muito tempo e dedicação. Dentre as palavras citadas, encontramos: dedicação, reflexão, estudo, experiências, cansaço e construção. Caracterizam as ideias dos alunos inclusos nessa categoria as expressóes: "Para fazer o Portfólio é preciso muito tempo e dedicação para se obter um bom produto final"; "Exige muita dedicação e vontade para desenvolvê-lo, uma vez que para a concretização desse trabalho é necessário buscar outras fontes de estudo, analisar e refletir os inúmeros temas que são propostos nesse trabalho. É preciso dedicação e tempo para sua realização"; "Para realizar um Portfólio eu estudo muito, pois tenho dificuldades para escrever, e isso é bom"; "O Portfólio é uma experiência nova que vem dando certo, mas ainda está um pouco confuso"; "Para que seja realizado um bom trabalho, é necessária muita dedicação, pessoal e do grupo"; "É um trabalho cansativo e, no mundo atual, a falta de tempo e o stress não nos permitem desenvolver um Portfólio excelente". 
O gráfico 1 permite comparar a frequência das resposta nas seis categorias de sentido identificadas.

Gráfico 1 - Distribuição percentual dos alunos, segundo a categoria de sentido em que se incluem

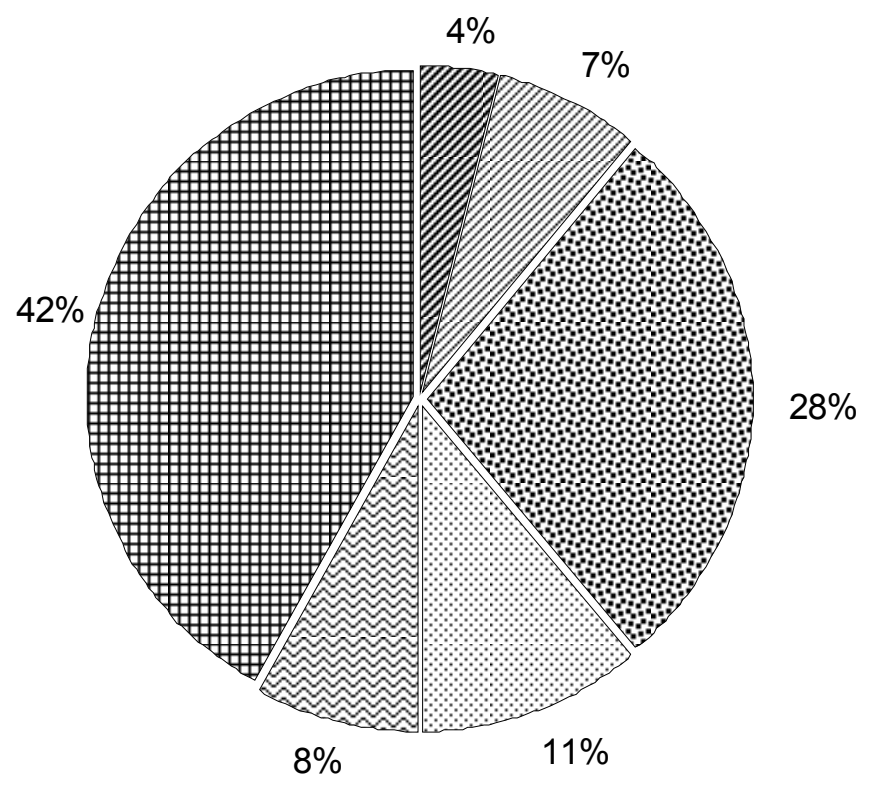

Os alunos sentem-se "incomodados" ou não consideram útil o uso do Portfólio

Apontam aspectos dificultadores na construção do Portfólio

[a Sentem-se "bem" construindo o Portfólio e consideram-no um instrumento confiável de avaliação

⿴囗大 Compreendem que o Portfólio é superior à avaliação classificatória - seletiva e excludente

ه Demonstram que a construção do Portfólio produz resultado satisfatório, mas exige tempo e dedicação

困 Apontam o Portfólio como facilitador na construção da aprendizagem 


\section{Análise do nível de aceitação e compreensáo do Portfólio pelos alunos}

Esse instrumento teve como objetivos:

a) Identificar o nível de aceitação inicial do Portfólio pelos alunos.

- A implantação e implementação do uso do Portfólio foi negociada ou imposta?

b) Apontar a compreensão dos alunos sobre a construção do Portfólio.

- o que é e quais seus princípios

- critérios de avaliação

- $\quad$ validade do instrumento como avaliaçáo

c) Perceber a importância do papel do professor/orientador ${ }^{5}$ na construção do Portfólio.

d) Evidenciar a importância da construção do Portfólio para a formação do educador.

- relevância ou não do Portfólio como instrumento avaliativo

e) Destacar aspectos negativos e positivos do Portfólio.

f) Identificar sentimentos em relação ao uso do Portfólio.

A análise dessas questôes, descritas de forma sintética, nos permitiu evidenciar que:

- a maioria dos licenciandos relata vivenciar uma experiência positiva com o uso do Portfólio, apesar de um número significativo afirmar ser essa prática imposta e causadora de insegurança;

- a maioria dos alunos aponta atribuiçóes positivas em relaçáo ao uso do Portfólio como instrumento avaliativo. Dentre outras, afirma que esse instrumento conduz à criatividade, promove a reflexão, favorece a autoavaliação e a autonomia;

- $\quad 70,8 \%$ dos entrevistados revelam que o Portfólio é um aprendizado que permite o desenvolvimento de novos modos de vivenciar o ensino-aprendizagem;

- quanto ao processo de implantação e implementação, quase a metade dos alunos, 46,6\%, não foi devidamente orientada e esclarecida;

- quase $70 \%$ dos alunos têm-se beneficiado com os horários destinados à orientação da construção do Portfólio, dado significativo para compreender a importância do papel do professor/orientador;

- a maioria dos alunos, $66,8 \%$, declara como aspecto facilitador na construção do Portfólio a liberdade de poder escrever por meio de diferentes linguagens e expressóes;

\footnotetext{
${ }^{5} \mathrm{Na}$ instituição pesquisada, cada turma tinha na sua carga horária três módulos/aulas (4 aulas e meia) por semana, para receber orientaçóes acerca da construção do Portfólio.
} 
- como aspectos dificultadores, 53,9\% apontam o "tempo insuficiente para construí-lo", e 32,0\% consideram o Portfólio uma avaliação muito subjetiva;

- a maioria dos licenciandos percebe que o Portfólio oferece contribuiçóes positivas para a formaçáo docente; porém, quase 13\% acreditam que ele é um instrumento que não avalia;

- sobre as fragilidades ou riscos do uso do Portfólio como instrumento avaliativo, a maioria dos estudantes aponta que ele é uma ferramenta subjetiva: "o fazemos pensando em quem vai avaliá-lo”. Em seguida, aparece a alternativa: "o Portfólio exige muita pesquisa e leitura para sua construção", indicada por $30,9 \%$ dos alunos. Apenas $28 \%$ afirmaram que ele não apresenta questôes negativas.

\section{Análises da compreensão dos alunos sobre a construção do Portfólio}

Apresentamos aos licenciandos entrevistados 3 questóes: com base em sua experiência, explique o que é Portfólio; se um conhecido seu, estudante de outra instituição, que não conhece o Portfólio, perguntar o que você pensa desse instrumento de avaliação, o que responderia a ele? E, por último: caso você queira apontar mais alguma consideração sobre o Portfólio, aproveite o espaço abaixo.

A análise das respostas dessas questóes foi efetuada com o auxílio do programa ALCESTE que, segundo Oliveira, Gomes e Marques (2005, p. 158), "utiliza mecanismos independentes da análise do conteúdo, objetivando obter uma primeira classificaçáo estatística dos enunciados simples do corpus estudado”.

Ao ser processado, o programa ALCESTE gera um relatório que é o resultado da classificação do corpus, seguindo um padrão de coocorrência. Em seguida, o programa divide o material discursivo em classes.

Sobre a formação das classes, Oliveira, Gomes e Marques (2005, p. 167) afirmam que "as classes podem indicar diferentes representaçóes sociais, campos de imagens sobre um dado objeto ou somente diferentes aspectos de uma mesma representação". Nesse sentido, podemos afirmar que são os conteúdos e a relação desses com os fatores ligados ao plano geral de cada pesquisa que vão definir o seu significado.

Com base nas respostas das três questóes abertas, processamos três programas, um para cada questão.

Na primeira questão: "A partir de sua experiência, explique o que é Portfólio"; a análise elaborada pelo programa ALCESTE dividiu o corpus de resposta em 4 classes. 
Palavras como "onde", "refletir", "aula", "vivência”, "atividade" e "trabalho" caracterizam a primeira classe e indicam que para os licenciandos o Portfólio pode ser um espaço para vivenciar atividades reflexivas.

As palavras: "construção", “aprendizagem”, “avaliação”, “inovador”, "processo” e "busca" foram apontadas como as mais significativas da segunda classe: "Uma construção do saber".

O conteúdo da terceira classe demonstra que o Portfólio é um instrumento capaz de desenvolver a aprendizagem. Para esse grupo de licenciandos, o Portfólio auxilia não só no desenvolvimento do conhecimento como também provoca reflexóes e criatividade. Constituem as palavras mais significativas dessa classe: "desenvolve", "reflexão", "criatividade", "leitura", "autonomia" e o verbo "provocar".

$\mathrm{Na}$ quarta classe, os licenciandos, contrapondo-se às definiçôes das três primeiras classes, que apresentam o Portfólio com características positivas, apontam definiçóes ambíguas. Apesar de em alguns momentos aprovarem o seu uso, em outros afirmam ser um instrumento "chato" e de difícil compreensão. As palavras: "consegue", "diferente", "orientador", "método", "prova” e "tempo" foram consideradas como as mais significativas dessa classe.

Quanto à segunda questão: "Se um conhecido seu, estudante de outra instituição, que não conhece o Portfólio, perguntar o que você pensa desse instrumento de avaliação, o que lhe responderia”, a análise elaborada pelo programa ALCESTE dividiu também o corpus de resposta em 4 classes.

Na primeira classe, as palavras "formar", "avaliar", "desenvolver", "experiência”, "maneira" e "pesquisa" foram apontadas como as mais significativas o que deu origem ao título: "Portfólio, uma forma inovadora de avaliar". De modo geral, os licenciandos entrevistados diriam aos outros estudantes que não conhecem o Portfólio, que esse instrumento se apoia principalmente na pesquisa, e constitui-se em uma maneira diferente de avaliar.

"Portfólio: é bom, mas deveria ser construído individualmente" é o título da segunda classe. Nela, os licenciandos revelam insatisfação por construir o Portfólio em grupo, e sugerem que seja feito individualmente. As palavras: "individual", "aprendizagem", "deveria”, "grupo", "ideia", "trabalho" e "curso" foram apontadas como as mais significativas dessa classe.

As palavras mais expressivas da terceira classe, "Portfólio: é bom, quando bem orientado", apontadas pelo ALCESTE, são: "avaliadores", "bom", "formação", "instrumento", "orientado” e "profissional”. Para os estudantes que re- 
presentam essa classe o Portfólio pode ser um bom instrumento de avaliação, desde que seja bem orientado. Atribuem às intervençóes do orientador o sucesso do Portfólio. Afirmam que esse instrumento só funciona se levado a sério pelo orientador e aluno.

Na quarta classe, "Portfólio deixa muito a desejar como um instrumento de avaliação", as palavras mais apontadas pelo ALCESTE são: "avalia", "curso", "método", "não" e "professor". Para os alunos que compóem essa classe, o Portfólio deixa a desejar como instrumento de avaliação. Afirmam que ele não avalia como deveria, $\mathrm{e}$ quando usado isoladamente não se constitui em um método seguro.

Quanto à terceira questão: "Caso você queira apontar mais alguma consideração sobre o Portfólio, aproveite o espaço abaixo”, a análise elaborada pelo programa ALCESTE dividiu o corpus de resposta em 2 classes. Depois dessa divisão e de leituras exaustivas dos conjuntos semânticos oferecidos pelo ALCESTE, atribuímos nomes a cada uma das classes.

Na primeira classe, "Portfólio: construção coletiva versus individual", os licenciandos queixam-se principalmente de o Portfólio ser realizado apenas em grupo e não individualmente. As palavras: "individual", "deveria", "curso" e "avaliação" foram as mais significativas dessa classe.

"A subjetividade do orientador como fragilidade na construção do Portfólio" é o título da segunda classe. Para os alunos, representantes dessa classe, a construção do Portfólio é influenciada por intervençóes negativas dos professores orientadores. $\mathrm{O}$ foco principal dessa classe assinala as queixas em relaçáo à subjetividade do orientador nas suas intervençóes. Reclamam da falta de esclarecimento e de consenso, por parte dos orientadores, do que seja realmente um trabalho por meio de Portfólio. As palavras mais significativas dessa classe são: "autonomia”, "orientador", "construção", "Portfólio", "curso" e "ideia".

\section{CONSIDERAÇÕES FINAIS}

A análise dos significados da avaliação da aprendizagem, por alunos concluintes de cursos de licenciaturas de uma IES, com base em suas experiências com o Portfólio como instrumento avaliativo, permitiu identificar três grupos de alunos: grupo $\mathrm{A}$, os que aprovam o Portfólio; grupo B, os que não aprovam o Portfólio; grupo $\mathrm{C}$, os que aprovam, porém com ressalvas.

Essa identificação, feita com base nas análises dos resultados, permitiu-nos compreender os significados que se organizam e definem, para cada um desses grupos 
de alunos, o sentido do Portfólio, possibilitando, assim, analisar as representaçóes construídas por eles.

Assim, pode-se afirmar que o primeiro grupo, a maioria dos alunos pesquisados, aprova o Portfólio como instrumento avaliativo e o considera uma forma de minimizar avaliaçóes que punem, excluem e selecionam. A minoria, ou seja, o segundo grupo, não acredita nessa forma de avaliar. E o terceiro grupo, com representatividade intermediária entre o primeiro e o segundo grupo, apoia o Portfólio como instrumento avaliativo, mas apresenta restriçóes e alertas que devem ser levadas em conta.

O conteúdo das respostas desses grupos evidenciou também que o Portfólio é visto como uma ferramenta para a construção do conhecimento, como uma vivência de um processo de avaliaçáo e como uma atividade muito subjetiva que não avalia.

A forma como se organizam os elementos constituintes da representaçáo e o percurso por meio do qual tais elementos adquirem materialidade e se tornam expressóes de uma realidade pensada como natural constituem a objetivação (Vala, 2004, p. 465). Portanto, analisar um processo de objetivação consiste em identificar os elementos que dáo sentido ao objeto.

Para não reprovar diretamente o uso do Portfólio, o aluno procura argumentos desviantes, meias verdades, que realmente não justificam a negaçáo do uso, mas atuam no sentido de construir uma visão de que esse instrumento é um processo difícil, exige muito tempo e é subjetivo.

$\mathrm{O}$ argumento da subjetividade, integrado em uma avaliação e utilizado para negá-la, para mantê-la como classificatória e excludente, não é novo. Já nos anos sessenta, Stake (apud Vieira, Sousa, 2008) procurava argumentar sobre a importância de compreender a subjetividade como necessária e, dessa forma, presente em qualquer processo avaliativo. Ser subjetivo não significa ser inadequado ou arbitrário. Na construção dessa representação, os argumentos a respeito da subjetividade são tidos como negativos e encobrem a falsa concepção de que ser objetivo é bom, e que há a possibilidade de uma avaliação, feita unicamente por prova, ser isenta de subjetividade.

A visão contrária ao Portfólio é construída utilizando-se a argumentação da falta de tempo, o que de fato é um ponto importante e efetivo. Contudo, o uso de Portfólio nessa instituiçáo prevê tempos diferenciados no contrato de trabalho do professor e na disponibilidade de estudo do aluno. Cada turma tem, na sua carga horária, três módulos/aulas (4 aulas e meia) por semana, para receber orientaçóes 
acerca da construção do Portfólio. Assim, o argumento da falta de tempo não se aplica e é utilizado fora do contexto; constitui-se, nesse sentido, em meia verdade.

Já os argumentos quanto "às orientaçôes de construção do Portfólio, à relação professor/orientador/aluno e à aprendizagem” indicam que os estudantes evidenciam outras necessidades não obrigatoriamente ligadas à avaliação.

Essa representação nos remete a Sousa (1998, p. 171), quando afirma que o grande problema que enfrentamos diz respeito a como ensinar e náo a como avaliar, e que "avaliar exige um profundo estudo sobre aprendizagens e uma postura política comprometida com o processo de transformação social”. Com os resultados apontados nesta pesquisa, entendemos que, seja qual for o instrumento de avaliaçáo, ele deve contribuir para o aperfeiçoamento do processo de ensino-aprendizagem e não apenas constituir-se em um fim em si mesmo. Nesse sentido, o Portfólio, empregado como instrumento avaliativo, deve apresentar coerência entre seu objetivo e o processo de aprendizagem.

Concluindo, podemos afirmar que a implantação do Portfólio na instituição pesquisada apresenta possibilidades de aceitação entre os estudantes e, ao mesmo tempo, cria representaçóes que irão dificultar seu uso posterior pelos próprios alunos. Como que antecipando suas dificuldades futuras, ou mesmo para não se comprometer com essa possibilidade, o aluno constrói representaçóes que lhe permitam justificar a não utilização de um instrumento tão completo e inclusivo.

\section{REFERÊNCIAS BIBLIOGRÁFICAS}

ABRIC, J. C. A Abordagem estrutural das representações sociais. In: MOREIRA, A. S. P.; OLIVEIRA, D. C. (Org.). Estudos interdisciplinares de representação social. 2.ed. Goiânia: $A B$ Editora, 2000. p. 27-38.

FRANCO, M. L. P. B. Análise de conteúdo. Brasília: Plano Editora, 2003.

HERNÁNDEZ, F. Cultura visual: mudança educativa e projeto de trabalho. Porto Alegre: Artmed, 2000.

Transgressão e mudança na educação: os projetos de trabalho. Porto Alegre: Artmed, 1998.

HOUAISS, Antônio; VILLAR, Mauro de Salles. Dicionário Houaiss da língua portuguesa. Rio de Janeiro: Objetiva, 2001.

JODELET, D. Representações sociais: um domínio em expansão. In: MOSCOVICl, S. A Representação social da psicanálise. Rio de Janeiro: Zahar, 2001.

MOSCOVICl, S. Representações sociais: investigações em psicologia social. Petrópolis: Vozes, 2003.

NASCIMENTO, A. F. M. ; LASSANCE, R. Avaliação de programas projetos eatividades universitárias: referenciando a prática. Brasília: Universa, 2000.

OLIVEIRA, D. C.; GOMES, A. M. T.; MARQUES, S. C. Análise estatística de dados textuais na pesquisa das representações sociais: alguns princípios e uma aplicação ao campo da saúde. In: MENIN, M. S.; SHIMIZU, A. M. (Org.). Experiência e representação social: questões teóricas e metodológicas. São Paulo: Casa do 
Psicólogo, 2005.

SÁ, C. P. Núcleo central das representações sociais. 2.ed. Petrópolis: Vozes, 2002.

SOUSA, C. Porta-fólios: um instrumento de avaliação de processos de formação, investigação e intervenção. In: ALMEIDA, L. S.; TAVARES, J. Conhecer, aprender, avaliar. Portugal: Porto Editora, 1998. p. 143-157.

VALA, J. Representações sociais e psicologia social do conhecimento quotidiano. In: VALA, J.; MONTEIRO, M. B. (Org.). Psicologia social. Lisboa: Fundação Calouste Gulbenkian, 2004, p. 457-502.

VIANNA, H. M. Avaliação do rendimento escolar e a interação aluno-professor. Estudos em Avaliação Educacional, n. 7, p. 89-94, 1993.

VIEIRA, V. M. O. Representações sociais e avaliação educacional: o que revela o Portfólio. 2006. Tese (Doutorado em Psicologia da Educação) - Pontifícia Universidade Católica de São Paulo. interações professor-orientador alunos no trabalho de construção de aprendizagens. In: CONGRESSO ESTADUAL PAULISTA SOBRE FORMAÇÃO DE EDUCADORES, 60, 2003, Águas de Lindóia. Anais..., 2003.

VIEIRA, V. M. O.; SOUSA, C. P. Algumas contribuições teóricas para a formação de professores sobre avaliação educacional: dos clássicos ao Portfólio como instrumento de avaliação. In: DONATONI, Rita Alaíde. (Org.). Avaliação escolar e formação de professores. 1.ed. Campinas: Alinea, 2008, v. 1, p. 171-225. VILLAS BOAS, B. M. F. A Avaliação formativa: em busca do desenvolvimento do aluno, do professor e da escola. In: VEIGA, I. P.; FONSECA, M. (Org.). As Dimensões do projeto políticopedagógico: novos desafios para a escola. Campinas: Papirus, 2001.

VILLAS BOAS, L. P. S. Jogo didático: um estudo de representações sociais. 2003. Tese (Mestrado em Psicologia da Educação) - Pontifícia Universidade Católica de São Paulo.

Recebido em: abril 2009

Aprovado para publicação em: maio 2009 